European Journal of Sustainable Development Research

2019, 3(4), em0094

ISSN: 2542-4742

\title{
A Thermodynamic Study of Rice Husk (Oryza Sativa) Pyrolysis
}

\author{
Adewale George Adeniyi ${ }^{1 *}$, Temitope Elizabeth Odetoye ${ }^{1}$, James Titiloye ${ }^{2}$, Joshua O. Ighalo ${ }^{1}$ \\ ${ }^{1}$ Chemical Engineering Department, Faculty of Engineering and Technology, University of Ilorin, Ilorin, P. M. B. 1515, \\ NIGERIA \\ ${ }^{2}$ Department of Chemical and Biological Process Engineering, Swansea University, Swansea, UNITED KINGDOM
}

*Corresponding Author: adeniyi.ag@unilorin.edu.ng

Citation: Adeniyi, A. G., Odetoye, T. E., Titiloye, J. and Ighalo, J. O. (2019). A Thermodynamic Study of Rice Husk (Oryza Sativa) Pyrolysis. European Journal of Sustainable Development Research, 3(4), em0094. https://doi.org/10.29333/ejosdr/5830

Published: June 29, 2019

\begin{abstract}
Rice (Oryza sativa) is one of the major agricultural products of tropical West Africa in general and Nigeria in particular. In this study ASPEN plus V8.8 was used to develop a thermodynamic model for the pyrolysis of rice husk. The model was validated and found to be accurate especially on the domain of oil and gas yields. It was used to study the effect of temperature on the product yield and oil composition. The fluid products increase with temperature and an optimum of $60 \%$ can be obtained from rice husk. The optimum oil yield was $44.2 \%$ obtained at $400^{\circ} \mathrm{C}$. The synthesis gas was composed basically of hydrogen gas, methane and traces of higher hydrocarbons, the char consisted of carbon and silicon oxide ash while the oil was madeup of acidic organic compounds, aldehydes, pyrolytic water and others. At $600^{\circ} \mathrm{C}$, the predictions revealed an oil composition of $84.7 \%$ acids, $7.9 \%$ pyrolytic water, $7.42 \%$ aldehyde and traces of alcohol and other compounds. The results from the thermodynamic predictions showed that rice husk is an excellent feedstock for the biofuels production via the thermo-chemical energy conversion route. The study has provided a useful framework for proper comparisons of the energy potential between different biomass feedstock.
\end{abstract}

Keywords: rice husk, pyrolysis, Aspen, simulation, thermodynamics, bio-oil, modelling

\section{INTRODUCTION}

Biomass has come into focus as a potential source of renewable energy due to the increasing demand of energy, depleting fossil fuel reserves and growing environmental sustainability concerns (Titiloye et al., 2013). Recently, researchers have also began exploring the performance and environmental impact mitigation of biofuels in practical use (Dhinesh and Annamalai, 2018; Nanthagopal et al., 2019; Vigneswaran et al., 2018). Biomass can be converted into useful forms of energy via different novel thermochemical and biochemical conversion techniques (Collard and Blin, 2014; Isahak et al., 2012; Jahirul et al., 2012; Lim et al., 2012; Panwar et al., 2012; Sharma et al., 2015). The energy is in the form of bio-fuels which has multiple applications. Thermochemical methods includes direct combustion, steam reforming, pyrolysis and gasification while biochemical methods includes the anaerobic digestion and fermentation processes (Isahak et al., 2012; Jahirul et al., 2012; Lim et al., 2012; Panwar et al., 2012). Pyrolysis is a very popular technique utilised in the recovery of energy from biomass residues and is the focus of this research work.

Rice is one of the major agricultural products of tropical West Africa and Nigeria in particular. It is a monocotyledonous plant of the genus Oryza and it consists of two cultivated species and 21 wild species (Lim et al., 2012). The cultivated species, Oryza sativa and Oryza glaberrism originate from Asia and Africa, respectively. Oryza 
sativa has superior yield and milling quality and is commercially grown in 112 countries from all continents. On the other hand, Oryza glaberrism is a semi-aquatic plant which is only grown in the West Africa region (Lim et al., 2012). The by-product from the milling of rice is the husk. It is currently being disposed in Nigeria by incineration. Rice husk biomass is a rich feedstock for energy recovery processes (Quispe et al., 2017) and it is readily available especially in most west African countries (Mansaray and Ghaly, 1997). The nature and yield of the pyrolysis products has been shown to be dependent on the distribution of hemicellulose, cellulose and lignin in the biomass (Gani and Naruse, 2007; Qu et al., 2011) and several studies over the years have attempted to get a better understanding on rice husk pyrolysis yield as a function of product composition.

The experimental thermochemical conversion of rice husk to useful products via the pyrolysis technique has been investigated over the years. Tsai et al. (2007) studied the product yield and composition from the pyrolysis of rice husk in a fixed bed tubular reactor. An oil yield of just above $40 \%$ was observed at the optimal temperature of about $500^{\circ} \mathrm{C}$. Alvarez et al. (2014) utilised a conical spouted bed reactor for bio-oil production from rice husk pyrolysis. A maximum bio-oil yield $(70 \mathrm{wt} . \%)$ was achieved at $450^{\circ} \mathrm{C}$, with low gas yield $(4 \mathrm{wt} . \%)$. Natarajan and Ganapathy (2009) also investigated the pyrolysis of rice husk in a fixed bed reactor. A maximum of about $31 \%$ oil yield was obtained at $500^{\circ} \mathrm{C}$. Williams and Nugranad (2000) compared products from catalytic and uncatalysed pyrolysis of rice husk. It was observed that he pyrolysis oils before catalysis were more homogeneous, of low viscosity and highly oxygenated. Polycyclic aromatic hydrocarbons (PAH) were present in the oils at low concentration and increased in concentration with increasing temperature of pyrolysis. The results obtained from experimental studies are mostly dependent on the nature of reactor, heating rate and other extraneous factors. These are not suitable for proper comparative evaluations of energy potential between different feedstock reported in open literature. Hence the need for thermodynamic predictions of product yield. Also different kinds of simulation and kinetic models for energy recovery from rice residues have been developed and validated (Mansaray et al. 2000a; 2000b; 2000c; Nikoo and Mahinpey, 2008) but they have come in the domain of gasification.

Based on the brief review presented above, it can be observed that there are no reports of the modelling of the pyrolysis of rice husk based on a thermodynamic approach. Haven previously examined biomass feedstock such as sugarcane bagasse (Adeniyi et al., 2019a) and banana residues (Adeniyi et al., 2019b), we proceed to study rice husks in this paper and plug in the knowledge gap. This study utilised ASPEN plus V8.8 to develop a thermodynamic model for the pyrolysis of Rice (Oryza sativa) husk. The model was validated and used to study the effect of temperature on the product yield and oil composition. Thermodynamic models such are these are used to predict the nature and composition of the product stream based solely on the compositional nature of the feed and the levels of process parameters such as temperature (Adeniyi et al., 2019d). Other extraneous factors available in experimental studies are invariably eliminated and prediction results are findings at chemical and phase equilibrium. Studies like these help to paint a true picture of how these process factor affect product yield and portray the true potential of the biomass for oil or char production from pyrolysis and provide an unbiased basis for proper comparisons of the energy potential between different biomass feedstock.

\section{METHODOLOGY}

Softwares such as ASPEN Plus V8.8 have been developed for the simulation and modelling of chemical process systems and can undertake calculations on mass and heat transfer, material and energy balance, phase and chemical equilibrium among others. Advantages of using the software for modelling includes fast and accurate calculations (including rigorous and iterative ones), optimisations, easier imposition of design specifications and constraints and better sensitivity analysis. It can be used for process design, modelling and integration (Adeniyi et al. 2018b, 2018c; Magnusson, 2005; Ward et al., 2014; Ye et al., 2009), feasibility studies (Naidoo, 2018), thermodynamic analysis (Adeniyi and Ighalo, 2018; Goicoechea et al., 2015; Xie et al., 2014), life cycle assessment (Altayeb, 2015; Peters et al., 2015; Sajid et al., 2016), energy and exergy analysis (Ofari-Boateng et al., 2012), green-house-gas assessment (Martinez-Hernandez et al., 2014), cost analysis (Santana et al., 2010) among other industrial applications and research application (Adeniyi et al., 2018a; Onarheim et al., 2014; Wang et al., 2011; Yan and Zhang, 1999).

In this study, a thermodynamic model was developed for the pyrolysis of rice husk. The specific reactor block for the model is RGIBBS. This block does calculations of chemical and phase equilibrium by the minimisation of Gibbs free energy. More detailed theoretical background is available in open literature (Adeniyi et al., 2019d). If the temperature and pressure of the system are kept constant, then its equilibrium can be shown as expressed in equation 1. 
European Journal of Sustainable Development Research, 3(4), em0094

Table 1. Proximate, Ultimate and Chemical Analysis of Rice (Oryza sativa) husk (Titiloye et al. 2013)

\begin{tabular}{lc}
\hline & Proximate analysis (wt $\mathbf{0}$ wet basis) \\
\hline Moisture & 8.59 \\
\hline Fixed Carbon & 8.48 \\
\hline Volatile Matter & 58.22 \\
\hline Ash & 24.71 \\
\hline Carbon & Ultimate/Elemental analysis (wt $\%$ moisture free) \\
\hline Hydrogen & 34.9 \\
\hline Sulphur & 5.15 \\
\hline Oxygen & 0.64 \\
\hline Nitrogen & 59 \\
\hline Chlorine & 0.31 \\
\hline & $<0.01$ \\
\hline Cellulose & 37.34 \\
\hline Hemicelluloses & 10.07 \\
\hline Lignin & 41.08 \\
\hline Extractives & 11.51 \\
\hline
\end{tabular}

$$
d G=\sum_{i=1}^{K} \mu_{i} n_{i} d n_{i}
$$

where $G$ is Gibbs free energy, $n_{i}$ is number of moles of species $i, K$ is total number of chemical species in the reaction mixture and $\mu_{i}$ is chemical potential of species $i$. The objective is to find the set of $n_{i}$ values that will minimise the value of $G$. There are two approaches in proceeding from here; a stoichiometric and a nonstoichiometric approach. For the former, the system is described by a set of stoichiometrically independent reactions which are typically chosen arbitrarily from a set of possible reactions. The non-stoichiometric approach involves finding the equilibrium composition by the direct minimization of the Gibbs free energy for a given set of species (Adhikari et al. 2017a, 2017b). The non-stoichiometric approach is the more applied technique in open literature. In examining this approach, we will examine equation 2.

$$
G=\sum_{i=1}^{K} \mu_{i} n_{i}
$$

To find the value of $n_{i}$ that will minimize the value of $G$, then it is important that the value of $n_{i}$ be in mass balance.

$$
\sum_{i=1}^{K} a_{l i} n_{i}=b_{l}, l=1, \ldots, M
$$

where $a_{l i}$ is number of gram atoms of element $l$ in $1 \mathrm{~mol}$ of species $i, b_{l}$ is total number of gram atoms of element $l$ in the reaction mixture and $M$ is the total number of atomic elements. The above expressions can then be further expressed as equation 4

$$
G=\sum_{i=1}^{K} n_{i} \Delta G_{i}^{0}+R T \sum_{i=1}^{K} n_{i} \operatorname{Iny} y_{i}+R T \sum_{i=1}^{K} n_{i} \operatorname{In} P
$$

where $T$ is temperature, $P$ is pressure, $\Delta G_{i}^{0}$ is standard Gibbs free energy of the formation of species $i$ and $y_{i}$ is mole fraction of species $i$. At high temperatures and low pressure, the system is considered to be ideal (Adhikari et al. 2017a, 2017b). Equation 4 is the objective function. Process simulation softwares like ASPEN Plus utilise this objective function in the minimisation of Gibbs free energy calculation to obtain thermodynamically accurate results.

\section{Simulation Specifications}

The information needed to model rice husk in the simulation is the proximate and ultimate analysis. The results presented in Table 1 are from the experiments of Titiloye et al. (2013). The specific property methods for enthalpy and density for maize residues were set as HCOALGEN method and DGOALIGT method respectively.

Due to the diversity of oxygenated organic compounds in biomass bio-oil, it will be difficult to completely specify all chemical compounds in the simulation. The approach chosen is one taken by several other researchers (Iordanidis et al., 2006; Peters et al., 2013; Ward et al., 2014). This involves selecting a fewer array of compounds in the simulation in such a way that they serve as representatives for different classes of organic compounds. The 


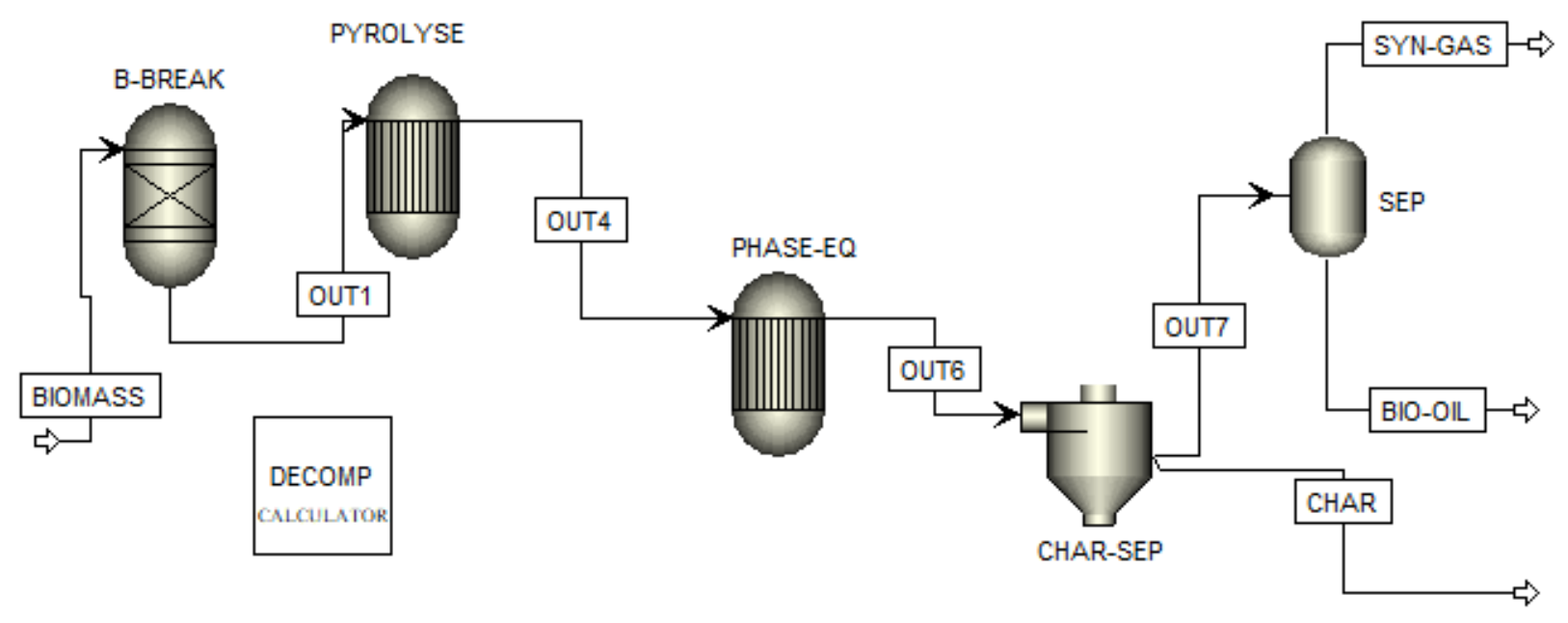

Figure 1. Process flow diagram for the pyrolysis simulation

approach by Iordanidis et al. (2006) is easy yet accurate. In implementing this approach (though with additions), the compounds included in the simulation were acetic acid, ethylene glycol, acetone, acetaldehyde, formic acid, methanol, formaldehyde, ethanol, phenol and water. The other compounds added were propanol, propionic acid, methyl acetate, ethyl formate and propionic acid. Other additions and justifications are elucidated in the proceeding discussions.

The non-conventional biomass feed will be broken into simulation components which will be the basic biomass constituents; cellulose, hemicellulose and lignin. In utilising the approach by Peters et al. (2013), hemicellulose and cellulose were represented in the simulation by their monomers: $\mathrm{C}_{5} \mathrm{H}_{8} \mathrm{O}_{4}$ (xylan) and $\mathrm{C}_{6} \mathrm{H}_{10} \mathrm{O}_{5}$ (xylose-like cellulose monomer), while lignin is represented by a Phenyl propane monomer. The ratios (by mass) of cellulose, hemicellulose and lignin were according to that of experiment (Titiloye et al., 2013) presented initially as mass percentages. The nitrogen content of the biomass is taken into account by including pyrrole to the simulation components while hydrogen sulphide gas accounts for all sulphur content. All sulphur in the simulation is considered as organic sulphur. For the synthesis gas composition, methane, ethane and hydrogen gas were also added to the simulation.

Carbon graphite $(\mathrm{mw}=12)$ was added to the simulation (as a solid) to represent char. The molecular was however adjusted to mimic coke by increasing the molecular weight to larger values (around $\mathrm{mw}=600$ ). Biomass ash majorly consists of silicon oxide and it is as high as $98 \%$ for rice husk (Alvarez et al., 2014). In this study it is assumed that the ash is made up of silicon oxide alone. The stream class was set as MIXCINC as there are solids, conventional and non-conventional components in the simulation. The global calculation method of the simulation was the Peng-Robinson with Boston-Mathias alpha function equation of state (PR-BM). Alpha is a temperature dependent parameter that improves the pure component vapour pressure correlation at very high temperatures and has been used in pyrolysis simulations on ASPEN plus (Adeniyi et al., 2019a).

\section{Process Description}

The flowsheet for the pyrolysis of rice (oryza sativa) husk was integrated in line with the aforementioned specifications. The process flow diagram is presented in Figure 1.

The feedstock is modelled as a non-conventional feed in the simulation. The RYIELD reactor (B-BREAK) block helps us decompose this feed into conventional simulation products. The calculator block was used to specify some restrictions/rules to which the RYIELD has to obey. The fixed carbon from the proximate analysis is equated to a carbon-graphite mass yield. Moisture is equated to a water mass yield, volatile matter is equated to the summation of cellulose, hemicellulose and lignin while ash is equated to silicon oxide solid. The software normalises the flowrate accordingly to ensure mass balance. This feed is then sent into a series of two RGIBBS reactors. The Gibbs reactor in ASPEN plus cannot simultaneously compute both phase and chemical equilibrium. Considering that the stream 'OUT1' consists of components in more than one phase, then the pyrolyser is modelled with this approach. The first RGIBBS reactor does the calculations of chemical equilibrium only according to the minimisation of Gibbs free energy method. The second Gibbs reactor does the calculations of phase equilibrium only. Both reactors are set at similar temperature and pressure conditions at all times. The solid phase (carbon graphite and silicon oxide ash) in the product stream (OUT 6) is separated by the cyclone to give the char and the liquid product is condensed to ambient conditions to obtain the bio-oil product stream and noncondensable gases. In cases where other feedstock was examined, the proximate and ultimate analysis input of the biomass stream is changed and the simulation was re-run. The range of temperature for the pyrolysis process 


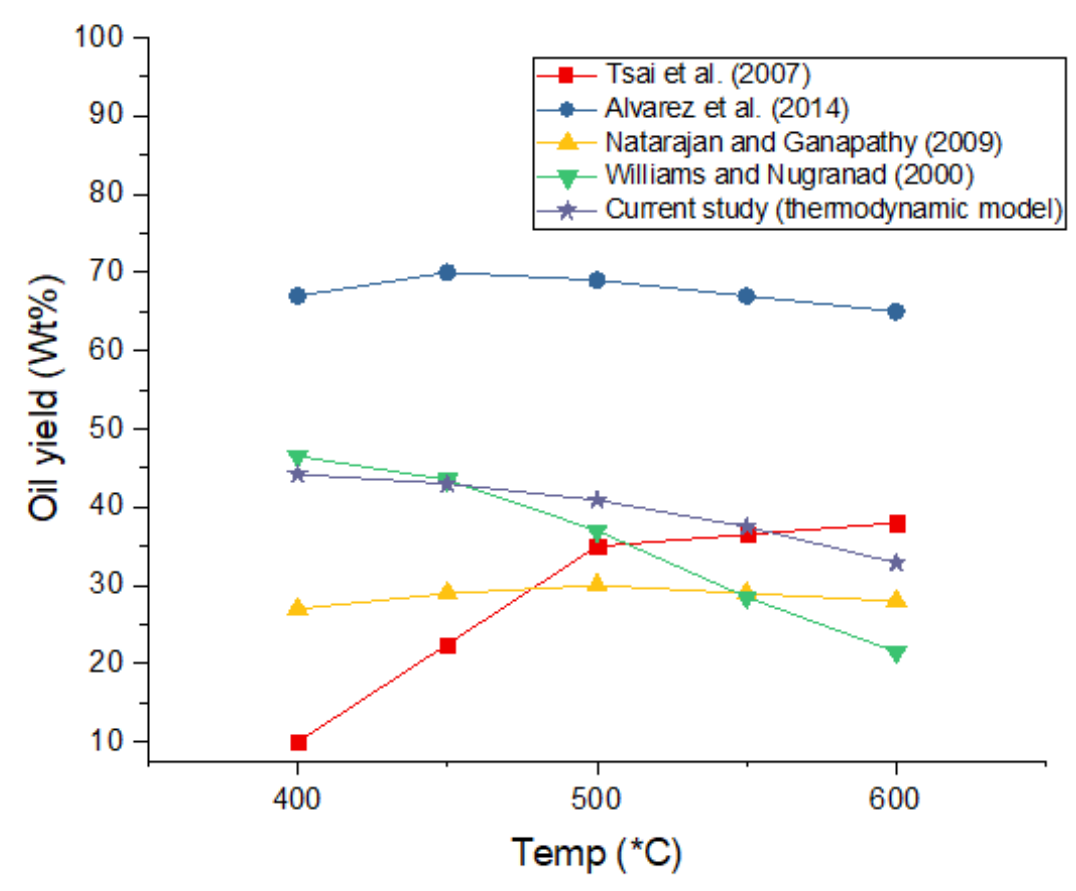

Figure 2. Simulation predictions of oil yield

considered in this work is between $400^{\circ} \mathrm{C}$ and $600^{\circ} \mathrm{C}$. This was chosen as most other experimental studies lied within this range.

\section{RESULTS AND DISCUSSION}

\section{Oil Yield}

The simulation was developed and run successfully according to the method described in the section above. Figure 2 shows the temperature sensitivity of the oil yield from the simulation in contrast with results obtained by other researchers. The optimum oil yield was $44.2 \%$ obtained at $400^{\circ} \mathrm{C}$. The oil yield drops gradually to $41 \%$ as process temperature increases to $500^{\circ} \mathrm{C}$. The oil yield then drops significantly to about $32.9 \%$ at $600^{\circ} \mathrm{C}$. The gradual drop in oil yield followed by a significant drop as the temperature increases is due to the more intense cracking of the larger polymer molecules at higher temperatures. This will result in a greater yield of lighter chemical species in the product stream. Based on this, we understand that oil yield will drop with increasing temperature. The thermodynamic predictions of oil yield based on the feedstock composition is in line with those of other studies except Tsai et al. (2007). Due to the vast differences in the results obtained by other researchers, it will be difficult to draw parallels between different studies. However, the thermodynamic predictions are fairly close to a mean plot of the experimental yields. The model results can be considered as ideal and considering only the chemical composition characteristics of the feedstock. Differences in reactor configuration, feedstock composition, heating technique and rate, process scale and other extraneous factors accounts for the deviations from the thermodynamic predictions presented. Bio-oil yield from the pyrolysis of rice husk is quite good and under optimised conditions the feedstock has the potential to be an excellent source of bio-oil for other applications.

\section{Gas Yield}

The thermodynamic predictions of gas yield are presented in Figure 3. The gas yield was lowest at $400^{\circ} \mathrm{C}$ and is about $17.1 \%$. Gas yield increases with increasing process temperature as is noticed in all studies. The optimum gas yield based on the thermodynamic predictions was $25.2 \%$ at $600^{\circ} \mathrm{C}$ (though it can go beyond this at higher temperatures at the expense of oil and char). The higher temperature results in a more intense cracking of the chemical species present in the system thereby leading to a higher proportion of small molecular weight molecules (lighter products). The model results can be considered as under-predictions when compared with those of Natarajan and Ganapathy (2009) and as over predictions when compared with those of Alvarez et al. (2014). The model predictions fairly resemble a plot of the mean of experimental results (especially at higher temperatures). 


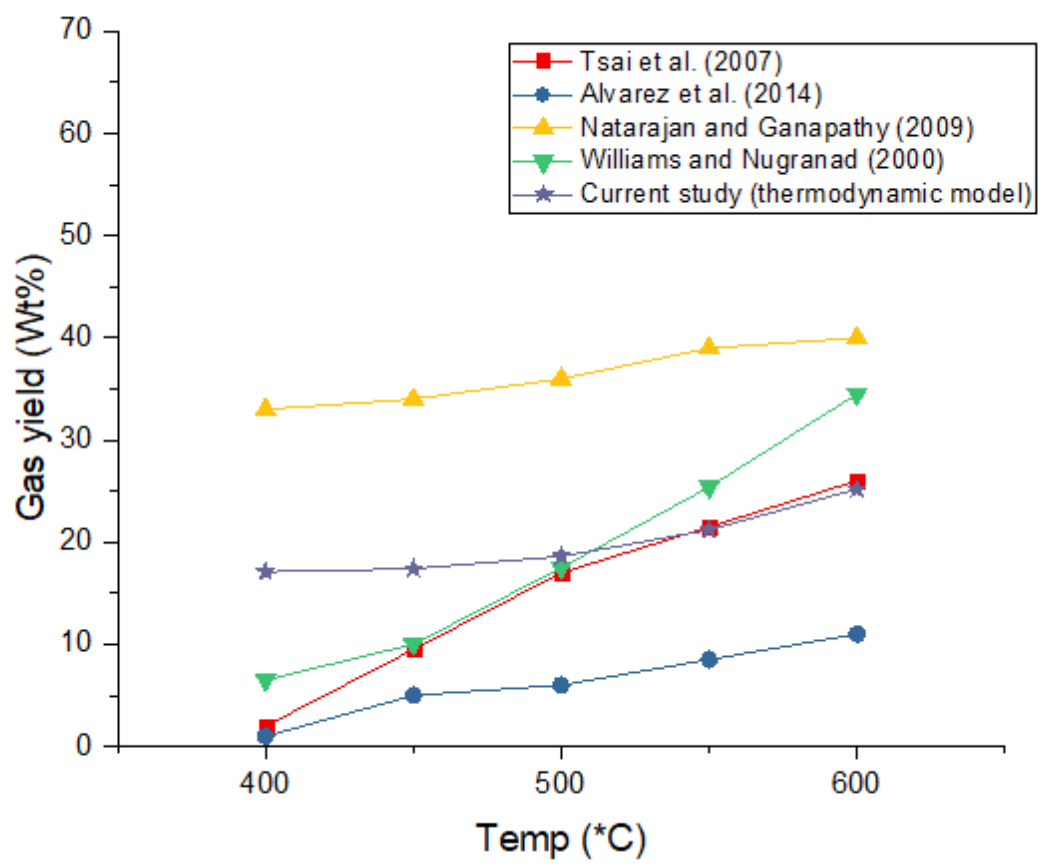

Figure 3. Simulation predictions of oil yield

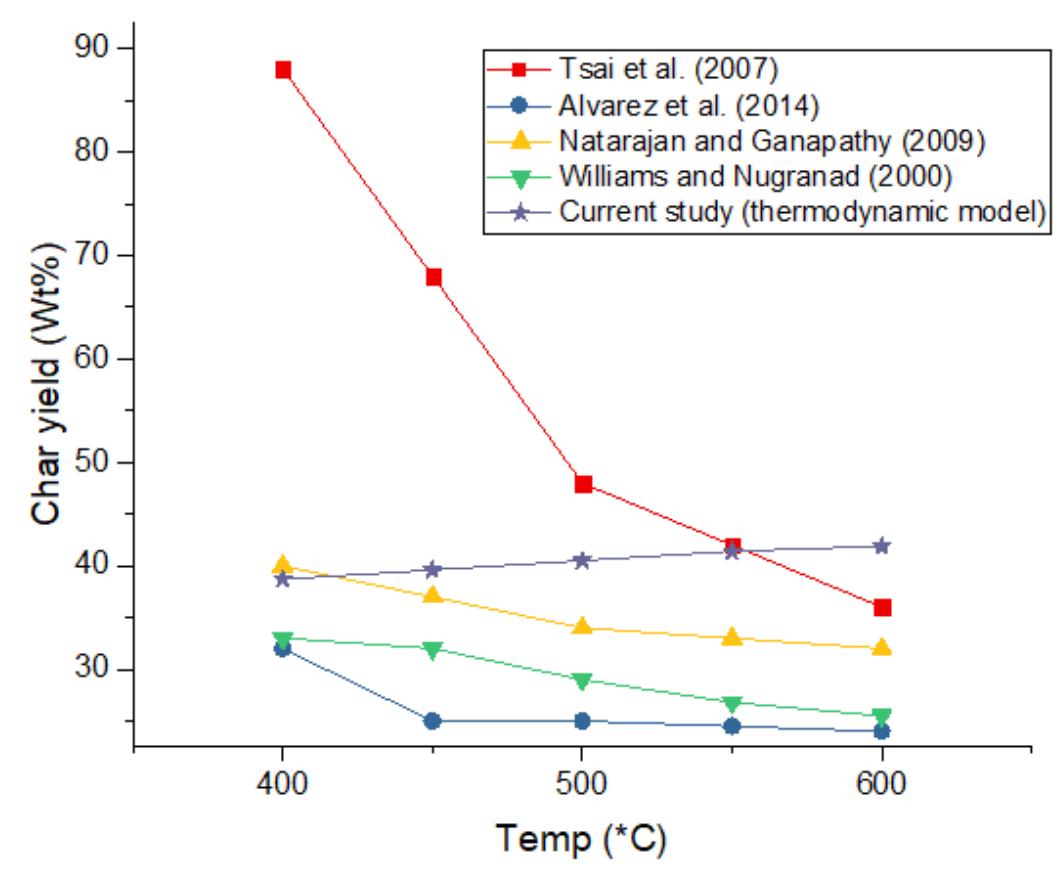

Figure 4. Simulation predictions of char yield

\section{Char Yield}

The yield of char with temperature is presented in Figure 4. Thermodynamic predictions of char yield as function of temperature change do not particularly follow those of experiments. While the usual trend from experiments is the drop of char yield with increasing temperature, simulation predictions show a slight increase in char yield with temperature. Though the yield increases from $38.7 \%$ to $41.9 \%$ between $400^{\circ} \mathrm{C}$ and $600^{\circ} \mathrm{C}$, this can also be considered as temperature insensitivity (in a more practical sense). Char formation reactions are nonequilibrium reactions and hence the current modelling approach will always find difficulty in capturing the process. It can be surmised that the model is insufficient in accurately predicting the temperature sensitivity of char during 


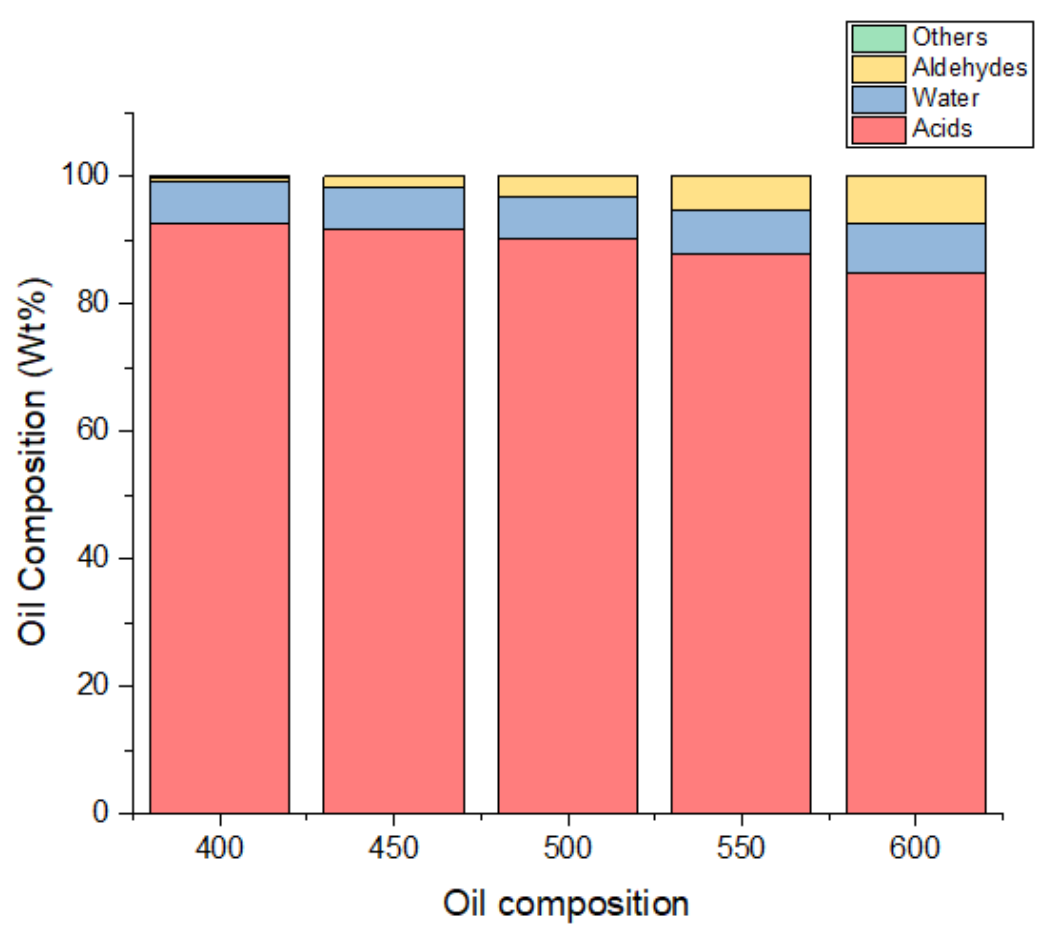

Figure 5. Oil composition with temperature

the simulation process. However, based on these predictions, rice husk will be an excellent feedstock for charoptimised thermochemical processes such as the recently designed gasification process by Adeniyi et al. (2019c).

Further validation was done with the results of Bakar and Titiloye $(2013)$ at $500^{\circ} \mathrm{C}$. The obtained pyrolysis product yields (for un-catalysed process) of $41.92 \%$ char, $39.61 \%$ oil and $18.47 \%$ gas. Using their feedstock characterisation (ultimate and proximate analysis) as input, simulation predictions at $500^{\circ} \mathrm{C}$ are $40.5 \%$ char, $40.9 \%$ oil and $18.6 \%$ gas.

\section{Product Composition}

The synthesis gas was composed basically of hydrogen gas and methane, with traces of higher molecular weight compounds and water vapour. The char consisted of carbon and silicon oxide ash. The oil was made-up of acidic organic compounds, aldehydes, pyrolytic water and others. Figure 5 presents the variation of oil composition with temperature. At $600^{\circ} \mathrm{C}$, the predictions revealed an oil composition of $84.7 \%$ acids, $7.9 \%$ pyrolytic water, $7.42 \%$ aldehyde and traces of alcohol and other compounds.

It is observed that the weight proportion of water, aldehydes and the other components (aromatics increased in the bio-oil obtained at higher temperatures while the organic acids reduced. This trend is valid as it has also been observed by Alvarez et al. (2014) though at varying proportions and with a wider plethora of organic compounds.

\section{CONCLUSION}

The temperature sensitivity of the simulation revealed that the oil yield drops gradually as process temperature increases and this was in line with those of other studies. This was accounted to the more intense cracking of the larger polymer molecules at higher temperatures. The optimum oil yield was $44.2 \%$ obtained at $400^{\circ} \mathrm{C}$. Gas yield increases with increasing process temperature as is noticed in all studies. The optimum gas yield based on the thermodynamic predictions was $25.2 \%$ at $600^{\circ} \mathrm{C}$ (though it can go beyond this at higher temperatures at the expense of oil and char). As much as $60 \%$ total fluid product can be obtained from the process. The synthesis gas was composed basically of hydrogen gas, methane and traces of higher hydrocarbons, the char consisted of carbon and silicon oxide ash while the oil was made-up of acidic organic compounds, aldehydes, pyrolytic water and others. At $600^{\circ} \mathrm{C}$, the predictions revealed an oil composition of $84.7 \%$ acids, $7.9 \%$ pyrolytic water, $7.42 \%$ aldehyde and traces of alcohol and other compounds. The study has set forth a basis for biomass pyrolysis in general and rice husk pyrolysis in particular based on a novel thermodynamic approach. Bio-fuel yield from the pyrolysis of rice husk is excellent and under optimised conditions the feedstock has the potential to be an excellent source of biooil for other applications. This study has also provided a modelling template for investigating the potentials of biomass samples for biofuel development based on the nature of the feed composition thereby providing a better framework for extensive comparative studies. 


\section{REFERENCES}

Adeniyi, A. G. and Ighalo, J. O. (2018). Study of Process Factor Effects and Interactions in Synthesis Gas Production via a Simulated Model for Glycerol Steam Reforming. Chemical Product and Process Modeling. https://doi.org/10.1515/cppm-2018-0034

Adeniyi, A. G., Adewoye, L. T. and Ighalo, J. O. (2018a). Computer Aided Simulation of the Pyrolysis of Waste Lubricating Oil using Aspen Hysys. Journal of Environmental Research, Engineering and Management, 74(2), 52-57. https://doi.org/10.5755/j01.erem.74.2.20537

Adeniyi, A. G., Eletta, A. A. O. and Ighalo, J. O. (2018b). Computer Aided Modelling of Low Density Polyethylene Pyrolysis To Produce Synthetic Fuels. Nigerian Journal of Technology, 37(4), 945-949. https://doi.org/10.4314/njt.v37i4.12

Adeniyi, A. G., Ighalo, J. O. and Abdulsalam, A. (2019a). Modelling of Integrated Processes for the Recovery of the Energetic Content of Sugarcane Bagasse. Biofuels, Bioproducts \& Biorefining. https://doi.org/10.1002/bbb.1998

Adeniyi, A. G., Ighalo, J. O. and Amosa, K. M. (2019b). Modelling and simulation of banana (Musa spp.) waste pyrolysis for bio-oil production. Biofuels. https://doi.org/10.1080/17597269.2018.1554949

Adeniyi, A. G., Ighalo, J. O. and Eletta, A. A. O. (2018c). Process Integration and Feedstock Optimisation of a Two-Step Biodiesel Production Process from Jatropha Curcas Using Aspen Plus. Chemical Product and Process Modelling. https://doi.org/10.1515/cppm-2018-0055

Adeniyi, A. G., Ighalo, J. O. and Onifade, D. V. (2019c). Production of biochar from elephant grass (Pernisetum purpureum) using an updraft biomass gasifier with retort heating. Biofuels. https:// doi.org/10.1080/17597269.2019.1613751

Adeniyi, A. G., Otoikhian, K. S. and Ighalo, J. O. (2019d). Steam Reforming of Biomass Pyrolysis Oil: A Review. International Journal of Chemical Reactor Engineering. https:/ / doi.org/10.1515/ijcre-2018-0328

Adhikari, S., et al. (2007a). A thermodynamic analysis of hydrogen production by steam reforming of glycerol. International Journal of Hydrogen Energy, 32(14), 2875-2880. https:/ / doi.org/10.1016/j.ijhydene.2007.03.023

Adhikari, S., Fernando, S. and Haryanto, A. (2007b). A comparative thermodynamic and experimental analysis on hydrogen production by steam reforming of glycerin. Energy \& Fuels, 21(4), 2306-2310. https://doi.org/10.1021/ef0700351

Altayeb, R. K. (2015). Liquid Fuel Production from Pyrolysis of Waste Tires: Process Simulation, Exergetic Analysis, And Life Cycle Assessment, in Department of chemical engineering. American University of Sharjah: Sharjah, United Arab Emirates.

Alvarez, J., et al. (2014). Bio-oil production from rice husk fast pyrolysis in a conical spouted bed reactor. Fuel, 128 , 162-169. https://doi.org/10.1016/j.fuel.2014.02.074

Bakar, M. S. A. and Titiloye, J. O. (2013). Catalytic pyrolysis of rice husk for bio-oil production. Journal of analytical and applied pyrolysis, 103, 362-368. https:// doi.org/10.1016/j.jaap.2012.09.005

Collard, F.-X. and Blin, J. (2014). A review on pyrolysis of biomass constituents: Mechanisms and composition of the products obtained from the conversion of cellulose, hemicelluloses and lignin. Renewable and Sustainable Energy Reviews, 38, 594-608. https:/ /doi.org/10.1016/j.rser.2014.06.013

Dhinesh, B. and Annamalai, M. (2018). A study on performance, combustion and emission behaviour of diesel engine powered by novel nano nerium oleander biofuel. Journal of cleaner production, 196, 74-83. https://doi.org/10.1016/j.jclepro.2018.06.002

Gani, A. and I. Naruse, Effect of cellulose and lignin content on pyrolysis and combustion characteristics for several types of biomass. Renewable Energy, 32(4), 649-661. https://doi.org/10.1016/j.renene.2006.02.017

Goicoechea, S., et al. (2015). Thermodynamic analysis of acetic acid steam reforming for hydrogen production. Journal of power sources, 279, 312-322. https:// doi.org/10.1016/j.jpowsour.2015.01.012

Iordanidis, A., et al. (2006). Autothermal sorption-enhanced steam reforming of bio-oil/biogas mixture and energy generation by fuel cells: Concept analysis and process simulation. International journal of hydrogen energy, 31(8), 1058-1065. https://doi.org/10.1016/j.ijhydene.2005.10.003

Isahak, W. N. R. W., et al. (2012). A review on bio-oil production from biomass by using pyrolysis method. Renewable and Sustainable Energy Reviews, 16(8), 5910-5923. https://doi.org/10.1016/j.rser.2012.05.039

Jahirul, M. I., et al. (2012). Biofuels production through biomass pyrolysis—a technological review. Energies, 5(12), 4952-5001. https://doi.org/10.3390/en5124952

Lim, J. S., et al. (2012). A review on utilisation of biomass from rice industry as a source of renewable energy. Renewable and Sustainable Energy Reviews, 16(5), 3084-3094. https://doi.org/10.1016/j.rser.2012.02.051

Magnusson, H. (2005). Process simulation in Aspen Plus of an integrated ethanol and CHP plant [Dissertation]. Sweden: Umea University. 
Mansaray, K. and Ghaly, A. (1997). Physical and thermochemical properties of rice husk. Energy Sources, 19(9), 9891004. https://doi.org/10.1080/00908319708908904

Mansaray, K., et al. (2000a). Mathematical modeling of a fluidized bed rice husk gasifier: Part I-Model development. Energy Sources, 22(1), 83-98. https:// doi.org/10.1080/00908310050014243

Mansaray, K., et al. (2000b). Mathematical modeling of a fluidized bed Rice Husk gasifier: Part II-model sensitivity. Energy sources, 22(2), 167-185. https://doi.org/10.1080/00908310050014144

Mansaray, K., et al. (2000c). Mathematical modeling of a fluidized bed rice husk gasifier: Part III-Model verification. Energy sources, 22(3), 281-296. https:// doi.org/10.1080/00908310050014063

Martinez-Hernandez, E., et al. (2014). Process integration, energy and GHG emission analyses of Jatropha-based biorefinery systems. Biomass Conversion and Biorefinery, 4(2), 105-124. https://doi.org/10.1007/s13399-013-01053

Naidoo, S. (2018). Feasibility study for maize as a feedstock for liquid fuels production based on a simulation developed in Aspen Plus ${ }^{\circledR}$.

Nanthagopal, K., et al. (2019). Investigation on diethyl ether as an additive with Calophyllum Inophyllum biodiesel for CI engine application. Energy Conversion and Management, 179, 104-113. https://doi.org/10.1016/j.enconman.2018.10.064

Natarajan, E. and Ganapathy, S. E. (2009). Pyrolysis of rice husk in a fixed bed reactor. World Academy of Science, Engineering and Technology, 56, 504-508.

Nikoo, M. B. and Mahinpey, N. (2008). Simulation of biomass gasification in fluidized bed reactor using ASPEN PLUS. Biomass and Bioenergy, 32(12), 1245-1254. https://doi.org/10.1016/j.biombioe.2008.02.020

Ofari-Boateng, C., Keat, T. L. and JitKang, L. (2012). Sustainability assessment of microalgal biodiesel production processes: an exergetic analysis approach with Aspen Plus. International Journal of Exergy, 10(4), 400-416. https://doi.org/10.1504/IJEX.2012.047510

Onarheim, K., Solantausta, Y. and Lehto, J. (2014). Process simulation development of fast pyrolysis of wood using aspen plus. Energy \& Fuels, 29(1), 205-217. https://doi.org/10.1021/ef502023y

Panwar, N., Kothari, R. and Tyagi, V. (2012). Thermo chemical conversion of biomass-Eco friendly energy routes. Renewable and Sustainable Energy Reviews, 16(4), 1801-1816. https://doi.org/10.1016/j.rser.2012.01.024

Peters, J. F., Iribarren, D. and Dufour, J. (2013). Predictive pyrolysis process modelling in Aspen Plus. In 21st Eur biomass conf exbib.

Peters, J. F., Iribarren, D. and Dufour, J. (2015). Simulation and life cycle assessment of biofuel production via fast pyrolysis and hydroupgrading. Fuel, 139, 441-456. https://doi.org/10.1016/j.fuel.2014.09.014

Qu, T., et al. (2011). Experimental Study of Biomass Pyrolysis Based on Three Major Components: Hemicellulose, Cellulose, and Lignin. Industrial \& Engineering Chemistry Research, 50, 10424-10433. https://doi.org/10.1021/ie1025453

Quispe, I., Navia, R. and Kahhat, R. (2017). Energy potential from rice husk through direct combustion and fast pyrolysis: A review. Waste management, 59, 200-210. https://doi.org/10.1016/j.wasman.2016.10.001

Sajid, Z., Khan, F. and Zhang, Y. (2016). Process simulation and life cycle analysis of biodiesel production. Renewable Energy, 85, 945-952. https://doi.org/10.1016/j.renene.2015.07.046

Santana, G., et al. (2010). Simulation and cost estimate for biodiesel production using castor oil. Chemical engineering research and design, 88(5-6), 626-632. https:// doi.org/10.1016/j.cherd.2009.09.015

Sharma, A., Pareek, V. and Zhang, D. (2015). Biomass pyrolysis-A review of modelling, process parameters and catalytic studies. Renewable and Sustainable Energy Reviews, 50, 1081-1096. https://doi.org/10.1016/j.rser.2015.04.193

Titiloye, J. O., Bakar, M. S. A. and Odetoye, T. E. (2013). Thermochemical characterisation of agricultural wastes from West Africa. Industrial crops and products, 47, 199-203. https://doi.org/10.1016/j.indcrop.2013.03.011

Tsai, W., Lee, M. and Chang, Y. (2007). Fast pyrolysis of rice husk: Product yields and compositions. Bioresource technology, 98(1), 22-28. https://doi.org/10.1016/j.biortech.2005.12.005

Vigneswaran, R., et al. (2018). Experimental investigation of unmodified diesel engine performance, combustion and emission with multipurpose additive along with water-in-diesel emulsion fuel. Energy conversion and management, 172, 370-380. https://doi.org/10.1016/j.enconman.2018.07.039

Wang, W., Shang, Y. and Wu, J. (2011). The lignite coal pyrolysis process simulation based on Aspen Plus. Chemical Industry and Engineering, 28(3), 49-53.

Ward, J., Rasul, M. G. and Bhuiya, M. M. K. (2014). Energy recovery from biomass by fast pyrolysis. Procedia Engineering, 90, 669-674. https://doi.org/10.1016/j.proeng.2014.11.791

Williams, P. T. and Nugranad, N. (2000). Comparison of products from the pyrolysis and catalytic pyrolysis of rice husks. Energy, 25(6), 493-513. https:/ / doi.org/10.1016/S0360-5442(00)00009-8 
Xie, H., et al. (2014). Thermodynamic analysis of hydrogen production from model compounds of bio - oil through steam reforming. Environmental Progress \& Sustainable Energy, 33(3), 1008-1016. https://doi.org/10.1002/ep.11846

Yan, H. and Zhang, D. (1999). Modeling of a low temperature pyrolysis process using ASPEN PLUS. Asia - Pacific Journal of Chemical Engineering, 7(5 - 6), 577-591. https://doi.org/10.1002/apj.5500070511

Ye, G., et al. (2009). Modeling of fluidized bed membrane reactors for hydrogen production from steam methane reforming with Aspen Plus. International journal of bydrogen energy, 34(11), 4755-4762. https:// doi.org/10.1016/j.ijhydene.2009.03.047 